\title{
Dentine sensitivity risk factors: A case-control study
}

\author{
Ana Cristina Mafla ${ }^{1}$, Luis Fernando Lopez-Moncayo ${ }^{1}$
}

Correspondence: Dr. Ana Cristina Mafla

Email: ana.mafla@campusucc.edu.co

'Dental Research Group, School of Dentistry, Cooperative University of Colombia, Pasto, Colombia

\section{ABSTRACT}

Objective: To identify the clinical and psychological risk factors associated with dentine hypersensitivity (DH) in order to provide an early diagnosis and preventive therapy. Materials and Methods: A nested case-control study was design between 2011 and 2012. A total of 61 DH cases and 122 controls participated in this investigation. Cases and controls were matched for sex, group of age and socioeconomic status in a ratio of 1:2. DH to different stimuli such as cold, heat, acid, and sweet was asked in patient interviews, and dental examinations were used to detect DH. Clinical and psychological risk factors such as dental hygiene, periodontal disease, acid diet, alcohol consumption, psychological stress, and psychopathological symptoms were inquired. Psychological stress was measured through the PSS-10 and psychopathological symptoms were evaluated by SCL-90-R in Spanish. Descriptive and univariate binary logistic regression analysis were performed to estimate the association between clinical and psychological risk factors and the presence of DH. Results: Toothpaste abrasivity (odds ratio [OR] 1.881, 95\% confidence interval [CI] 1.010-3.502, $P=0.045$ ), gingival recession (OR 2.196, 95\% CI 1.020-4.728, $P=0.041$ ), and periodontal therapy (OR 5.357, 95\% CI 2.051-13.993, $P<0.001$ ) were associated with DH. Subjects with perceived stress (OR $1.211,95 \%$, CI $0.518-2.833, P=0.658$ ), obsessive-compulsive (OR 1.266, 95\%, CI $0.494-3.240, P=0.623$ ) and hostility (OR $1.235,95 \%$, CI $0.507-3.007, P=0.642$ ) symptoms had a clinical greater odd of DH. Conclusion: Oral hygiene products and periodontal conditions are important risk factors for DH. Individuals with perceived stress, obsessive-compulsive, and hostility symptoms may increase a clinical risk for this entity. Targeting to dental counseling focused on oral hygiene products, periodontal therapy and a psychological evaluation may be promising in DH prevention.

Key words: Case-control studies, dentine sensitivity, oral hygiene, psychology, risk factors

\section{INTRODUCTION}

"Pain is an unpleasant sensory experience associated with actual or potential tissue damage or describe in terms of such damage."[1] Dentine hypersensitivity $(\mathrm{DH})$ as a state of uneasiness is a short, sharp pain arising from exposed dentine in response to stimuli, typically thermal, evaporative, tactile, osmotic, or chemical and which cannot be ascribed to any other dental defect or pathology ${ }^{[2]}$ and affects the quality of life substantially. ${ }^{[3]}$

The prevalence of $\mathrm{DH}$ is quite variable ranging from 1.3 to $68 \%{ }^{[4-8]}$ The occurrence of DH increases throughout life-course, peaking at 30-40 years of age. Further, sex differences have been found, with females more frequently affected than males, ${ }^{[7,8]}$ although not always statistically significant. ${ }^{[9]}$ Potential causes include progressive erosive tooth wear, ${ }^{[10]}$ vigorous tooth brushing, ${ }^{[11]}$ abfractions ${ }^{[12]}$ or gingival recession (GR). ${ }^{[13]}$ However, gaps still exist in our understanding as to the cause (s) of DH.

Psychological factors and oral health have emerged as important in our understanding of oral conditions and symptoms. Biopsychosocial model consider the contributions of biological, psychological, and social factors and their complex interactions in understanding

This is an open access article distributed under the terms of the Creative Commons Attribution-NonCommercial-ShareAlike 3.0 License, which allows others to remix, tweak, and build upon the work non-commercially, as long as the author is credited and the new creations are licensed under the identical terms.

For reprints contact: reprints@medknow.com

How to cite this article: Mafla AC, Lopez-Moncayo LF. Dentine sensitivity risk factors: A case-control study. Eur J Dent 2016;10:1-6.

DOI: $10.4103 / 1305-7456.175678$ 
health, illness, and health care delivery. ${ }^{[14]}$ Since psychological stress and psychopathological symptoms might be linked to the workings of the endocrine system, the immune system, and the nervous system, ${ }^{[15]}$ the study of their interrelationships may help in the comprehension of the nature of $\mathrm{DH}$.

An understanding of diverse factors associated with $\mathrm{DH}$ is important because some biological variables may not be good predictors of an individual's pain reports. Although a definitive treatment for $\mathrm{DH}$ may not materialize in the very near future, it is important to understand the clinical and psychological factors that contribute to the symptoms. A comprehensive approach should seek to prevent the disease, and enhance focused identification of new dental counseling and appropriate preventive therapy targets. For this reason, we designed a case-control study to identify those potential risk factors associated for $\mathrm{DH}$.

\section{MATERIALS AND METHODS}

\section{Sample and study design}

A nested case-control study was designed wherein individuals with diagnosis of $\mathrm{DH}$ were considered as "cases" and a group without diagnosis of DH as "controls". The cases and controls were nested 1:2 according sex, group of age and socio-economic status (SES). Patient volunteers were recruited from the general dentistry clinic from 2011 to 2012. During the study period, a total of 232 patients were included. A total of 61 out of 87 cases and 122 out 145 controls were selected and matched.

Study subjects comprised both males and females aged 15-44 years and from different SES. The sample included individuals of both sexes, because of sex-related differences are important in pain perception. Males and females differ in their responses to pain, with increased pain sensitivity and risk for clinical pain commonly more observed among women. ${ }^{[16]}$ Wiesenfeld-Hallin ${ }^{[17]}$ mentions these differences in pain sensitivity could be attributable to biological mechanisms such as sex hormones. We chose this age range because it has been reported that DH peaks between 30 and 40 years old ${ }^{[7]}$ and also, the literature suggests correlations among $\mathrm{DH}$, tooth wear and acidic beverages in this age range. ${ }^{[18]}$ Further, nesting the cases and controls by SES was important since greater pain disability has been reported in lower SES individuals. People in the lowest as compared to the highest SES were twice to 3 times more likely to feel disabled through pain. ${ }^{[19]}$
We excluded individuals whose tooth pain was related to pulp conditions, periodontal pockets and tooth damage, orthodontic appliances or removable dental prosthesis. These conditions probably could become confounding variables that can adversely affect the relation between other predisposing factors, such as psychological characteristics and the presence of $\mathrm{DH}$.

\section{Dentine hypersensitivity diagnosis}

Participants or their parents signed the written informed consent prior to the clinical examination. Patients were queried as to the presence of $\mathrm{DH}$ in response to cold, heat, acid, and sweet stimulation at the baseline patient interviews. During clinical examination, individual tooth sensitivity responses were elicited to evaporative (the air-dry syringe tip was positioned at a distance of $1 \mathrm{~cm}$ from the teeth), tactile (a dental explorer was used to assess the tooth surfaces from mesial to distal), thermal (small ice cubes were employed), and osmotic (sweet solution made with $15 \mathrm{~g}$ of anhydrous dextrose and $50 \mathrm{ml}$ of water was utilized). The evaluators made a careful observation of interproximal tooth surfaces in the clinical assessment. They assured these surfaces do not display color changes or become soft to the touch, especially in those subjects who perceived discomfort when osmotic method was used to evaluate sensitivity. Since only $1.4 \%^{[20]}$ of people report pain when they have intact crowns we decided do not expose to patients to any type of $X$-ray examinations to confirm the presence of interproximal dental caries.

\section{Risk factors}

Information about potential risk factors related to socio-demographic characteristics, dental hygiene, and periodontal disease, acid diet, alcohol consumption and psychological variables was provided by participants in a structured interview. In addition, presence of dental plaque, time, and frequency of tooth brushing, hand utilized to brush the teeth, type of toothbrush and toothpaste, presence of GR and whether they had received periodontal therapy in the last month specially scaling and root planning were obtained. Toothpaste was classified in relation to abrasivity according to a reported radioactive or relative dentine abrasivity (RDA), ${ }^{[21]}$ in low abrasivity $(\leq 70)$ and medium and high abrasivity $(>70)$.

We sought dietary information including the consumption of acidic beverages including natural and artificial fruit juices, carbonated and alcoholic drinks (a previous analysis was done for measuring $\mathrm{pH}$ beverages at the chemistry laboratory). 
Psychological factors were measured through levels of perceived stress with a simple evaluation scale, a well-documented perceived stress test Perceived Stress Scale (PSS-10) in Spanish version ${ }^{[22]}$ and psychopathological symptoms using the Symptom Checklist (SCL-90-R) in Spanish version. ${ }^{[23]}$ The latter scale is a self-report instrument designed to reflect nine symptoms of psychopathology seen in psychiatric and medical patients such as somatization, obsessive-compulsive, interpersonal sensitivity, depression, anxiety, anger-hostility, phobic anxiety, psychoticism, and paranoid ideation. ${ }^{[24]}$

\section{Statistical analysis}

Descriptive measures were performed to obtain the prevalence of DH. Risk factors were expressed as odds ratios (ORs) and 95\% confidence intervals (CI) and estimated by using a univariate binary logistic regression analysis. The level of statistical significance was set at $5 \%$. The data were analyzed with the Statistical Package for Social Sciences (SPSS 17.0, Inc., Chicago, IL, USA).

\section{RESULTS}

Among 61 study cases, $24.5 \%(n=15)$ were male and $75.5 \%(n=46)$ were female. Approximately, a female-to-male ratio was 3:1. Our findings showed individuals who used a toothpaste with a RDA higher than 70 (OR 1.881, 95\%, CI 1.010-3.502, $P=0.045$ ) had GR (OR 2.196, 95\%, CI 1.020-4.728, $P=0.041$ ), and received periodontal therapy in the last month (OR 5.357, 95\%, CI 2.051-13.993, $P<0.001$ ) increased the risk for $\mathrm{DH}$. There were some clinical but not statistical associations between $\mathrm{DH}$ and type of toothbrush bristles (OR 1.622, 95\%, CI 0.682-3.862, P=0.271), $\mathrm{pH}$ of artificial fruit juices (OR 2.431, 95\% CI 0.817-7.227, $P=0.105)$, carbonated drinks $\mathrm{p} / \mathrm{w}$ (OR 1.697, 95\%, CI 0.911-3.162, $P=0.094$ ), or $\mathrm{pH}$ of alcohol (OR 3.818, $95 \%$, CI $0.320-44.479, P=0.254)$ [Table 1].

There were no significant associations between $\mathrm{DH}$ and psychological factors. However, subjects with higher perceived psychological stress (OR 1.211, 95\%, CI 0.518-2.833 P=0.658), obsessive-compulsive (OR 1.266, 95\%, CI 0.494-3.240 P = 0.623) and hostility (OR 1.235, 95\%, CI 0.507-3.007 $P=0.642$ ) symptoms had a clinical greater odds of DH [Table 2].

\section{DISCUSSION}

Biological variations between females and males may make them differentially vulnerable to different oral

\begin{tabular}{|c|c|c|c|c|}
\hline Characteristic & Frequency & OR & CI $95 \%$ & $P^{*}$ \\
\hline \multicolumn{5}{|l|}{ Sociodemographic } \\
\hline \multicolumn{5}{|l|}{ Sex } \\
\hline Male & $15(33.3)$ & 0.957 & $0.490-2.042$ & 1.000 \\
\hline Female & $46(33.3)$ & & & \\
\hline \multicolumn{5}{|l|}{ Age (year-old) } \\
\hline $15-24$ & $26(33.3)$ & 1.000 & $0.541-1.849$ & 1.000 \\
\hline $25-34$ & $30(33.3)$ & 1.000 & $0.540-1.850$ & 1.000 \\
\hline $35-44$ & $5(33.3)$ & 1.000 & $0.326-3.066$ & 1.000 \\
\hline \multicolumn{5}{|l|}{$\begin{array}{l}\text { Socio-economic } \\
\text { stratum }\end{array}$} \\
\hline Low & $26(33.3)$ & 1.000 & $0.537-1.862$ & 1.000 \\
\hline Middle & 35 (33.3) & & & \\
\hline \multicolumn{5}{|l|}{$\begin{array}{l}\text { Dental hygiene and } \\
\text { periodontal disease }\end{array}$} \\
\hline \multicolumn{5}{|l|}{ Laterality } \\
\hline Right hand & $57(35.8)$ & 2.794 & $0.910-8.575$ & 0.063 \\
\hline Left hand & $4(21.1)$ & 0.501 & 0.159-1.579 & 0.230 \\
\hline Right and left hand & N/A & $\mathrm{N} / \mathrm{A}$ & $N / A$ & $\mathrm{~N} / \mathrm{A}$ \\
\hline \multicolumn{5}{|l|}{ Toothbrush shape } \\
\hline Flat $^{\star}$ & $8(25.0)$ & 0.616 & $0.259-1.467$ & 0.271 \\
\hline Uneven & $53(35.1)$ & & & \\
\hline \multicolumn{5}{|l|}{ Toothbrush bristles } \\
\hline Medium-hard* & $8(25.0)$ & 1.622 & $0.682-3.862$ & 0.271 \\
\hline Soft & $53(35.1)$ & & & \\
\hline \multicolumn{5}{|l|}{ Toothpaste abrasivity } \\
\hline$>70 \mathrm{RDA}^{*}$ & $33(41.3)$ & 1.881 & $1.010-3.502$ & 0.045 \\
\hline$\leq 70$ RDA & $28(27.2)$ & & & \\
\hline \multicolumn{5}{|l|}{ Tooth brushing time } \\
\hline$>1 \min ^{*}$ & $48(32.9)$ & 0.904 & $0.424-1.930$ & 0.795 \\
\hline$\leq 1 \mathrm{~min}$ & $13(35.1)$ & & & \\
\hline \multicolumn{5}{|l|}{$\begin{array}{l}\text { Tooth brushing } \\
\text { frequency }\end{array}$} \\
\hline$>2^{*}$ & $50(33.3)$ & 1.000 & $0.450-2.224$ & 1.000 \\
\hline$\leq 2$ & $11(33.3)$ & & & \\
\hline \multicolumn{5}{|l|}{ Dental plaque } \\
\hline Yes & $11(31.4)$ & 0.898 & $0.407-1.981$ & 0.790 \\
\hline No & $50(33.8)$ & & & \\
\hline \multicolumn{5}{|l|}{ Gingival recession } \\
\hline Yes & $16(48.5)$ & 2.196 & $1.020-4.728$ & 0.041 \\
\hline No & $45(30.0)$ & & & \\
\hline \multicolumn{5}{|l|}{$\begin{array}{l}\text { Periodontal therapy } \\
\text { (in the last month) }\end{array}$} \\
\hline Yes & $15(68.2)$ & 5.357 & $2.051-13.993$ & $<0.001$ \\
\hline No & $46(28.6)$ & & & \\
\hline \multicolumn{5}{|l|}{ Acid diet } \\
\hline \multicolumn{5}{|l|}{ Natural fruit juices $\mathrm{pH}$} \\
\hline $0-3^{*}$ & $18(35.3)$ & 1.050 & $0.527-2.093$ & 0.890 \\
\hline$>3$ & $40(34.2)$ & & & \\
\hline \multicolumn{5}{|l|}{$\begin{array}{l}\text { Frequency of natural } \\
\text { fruit juices } p / w\end{array}$} \\
\hline$>7^{*}$ & $5(16.7)$ & 0.346 & $0.126-0.956$ & 0.034 \\
\hline $0-7$ & $56(36.6)$ & & & \\
\hline
\end{tabular}

Contd... 
Mafla and Lopez-Moncayo: Dentine sensitivity risk factors

\begin{tabular}{|c|c|c|c|c|}
\hline Characteristic & Frequency & OR & $\mathrm{Cl} 95 \%$ & $P^{*}$ \\
\hline \multicolumn{5}{|c|}{ Artificial fruit juices $\mathrm{pH}$} \\
\hline $0-3^{*}$ & $10(35.7)$ & 2.431 & $0.817-7.227$ & 0.105 \\
\hline$>3$ & $8(18.6)$ & & & \\
\hline \multicolumn{5}{|c|}{$\begin{array}{l}\text { Frequency of artificial } \\
\text { fruit juices } \mathrm{p} / \mathrm{w}\end{array}$} \\
\hline $0-3$ & $9(29.0)$ & 0.787 & $0.338-1.831$ & 0.577 \\
\hline$>3^{*}$ & $52(34.2)$ & & & \\
\hline \multicolumn{5}{|c|}{ Carbonated drinks $\mathrm{pH}$} \\
\hline $0-3^{*}$ & $18(31.0)$ & 0.612 & $0.286-1.307$ & 0.203 \\
\hline$>3$ & $25(42.4)$ & & & \\
\hline \multicolumn{5}{|c|}{$\begin{array}{l}\text { Frequency of } \\
\text { carbonated drinks } \mathrm{p} / \mathrm{w}\end{array}$} \\
\hline $0-3$ & $36(39.1)$ & 1.697 & $0.911-3.162$ & 0.094 \\
\hline$>3^{*}$ & $25(27.5)$ & & & \\
\hline \multicolumn{5}{|c|}{ Total of beverages $\mathrm{pH}$} \\
\hline $0-3^{*}$ & $22(29.3)$ & 0.666 & $0.351-1.265$ & 0.214 \\
\hline$>3$ & $38(38.4)$ & & & \\
\hline \multicolumn{5}{|c|}{$\begin{array}{l}\text { Frequency of total } \\
\text { beverages intake } \mathrm{p} / \mathrm{w}\end{array}$} \\
\hline$>14^{*}$ & $9(28.1)$ & 0.745 & $0.321-1.727$ & 0.491 \\
\hline $0-14$ & $52(34.4)$ & & & \\
\hline \multicolumn{5}{|c|}{ Alcohol consumption } \\
\hline \multicolumn{5}{|c|}{ Alcohol pH } \\
\hline $0-4^{*}$ & $2(66.7)$ & 3.818 & $0.328-44.479$ & 0.254 \\
\hline$>4$ & $22(34.4)$ & & & \\
\hline \multicolumn{5}{|c|}{$\begin{array}{l}\text { Frequency of alcohol } \\
\text { consumption }\end{array}$} \\
\hline$>1^{*}$ & $2(28.6)$ & 0.793 & $0.149-4.211$ & 0.785 \\
\hline $0-1$ & $59(33.5)$ & & & \\
\hline
\end{tabular}

health problems. Even though case-control studies cannot provide any information about prevalence, we found there existed a difference in the number of females and males that were recruited in the "case" group (sex ratio $=3: 1$ ). The observed sex differences in this study may reflect the fact that more females than males seek care, as well as whether there are sex differences in DH prevalence. ${ }^{[25]}$ Pain sensitivity and risk for clinical pain commonly is more observed among women. ${ }^{[16]}$ However, if $\mathrm{DH}$ is more prevalent in females, emotional imbalances may be translated into this particular health problem, as well.

$\mathrm{DH}$ has been associated with diverse factors among them chronic trauma (tooth brushing), dental erosion, gastric regurgitation or dietary substances, anatomical aspects, and GR caused by periodontitis or periodontal surgery. ${ }^{[26]}$ Our outcomes revealed GR (OR 2.196, 95\%, CI 1.020-4.728, $P=0.041$ ) and periodontal therapy such as scaling and root planning (OR 5.357, 95\%, CI 2.051-13.993, $P<0.001$ ) were the major predisposing factors for DH. Rahiotis et al. and Costa et al..$^{77,8]}$ also

\begin{tabular}{|c|c|c|c|c|}
\hline Characteristic & Frequency & OR & $\mathrm{Cl} 95 \%$ & $P^{*}$ \\
\hline \multicolumn{5}{|c|}{ Psychological factors } \\
\hline \multicolumn{5}{|c|}{ Perceived stress } \\
\hline Yes & $10(37.0)$ & 1.211 & $0.518-2.833$ & 0.658 \\
\hline No & $51(32.7)$ & & & \\
\hline \multicolumn{5}{|l|}{ Somatization } \\
\hline Yes & $9(31.0)$ & 0.883 & $0.376-2.075$ & 0.775 \\
\hline No & $52(33.8)$ & & & \\
\hline \multicolumn{5}{|c|}{ Obsessive compulsive } \\
\hline Yes & $8(38.1)$ & 1.266 & $0.494-3.240$ & 0.623 \\
\hline No & $53(32.7)$ & & & \\
\hline \multicolumn{5}{|c|}{ Interpersonal sensitivity } \\
\hline Yes & $9(28.1)$ & 0.745 & $0.321-1.727$ & 0.491 \\
\hline No & $52(34.4)$ & & & \\
\hline \multicolumn{5}{|l|}{ Depression } \\
\hline Yes & $10(29.4)$ & 0.801 & $0.356-1.803$ & 0.591 \\
\hline No & $51(34.2)$ & & & \\
\hline \multicolumn{5}{|l|}{ Anxiety } \\
\hline Yes & $6(24.0)$ & 0.591 & $0.223-1.567$ & 0.287 \\
\hline No & $55(34.8)$ & & & \\
\hline \multicolumn{5}{|l|}{ Hostility } \\
\hline Yes & $9(37.5)$ & 1.235 & 0.507-3.007 & 0.642 \\
\hline No & $52(32.7)$ & & & \\
\hline \multicolumn{5}{|l|}{ Phobic anxiety } \\
\hline Yes & $9(28.1)$ & 0.745 & $0.321-1.727$ & 0.491 \\
\hline No & $52(34.4)$ & & & \\
\hline \multicolumn{5}{|c|}{ Paranoid ideation } \\
\hline Yes & $7(25.9)$ & 0.661 & $0.263-1.662$ & 0.377 \\
\hline No & $54(34.6)$ & & & \\
\hline \multicolumn{5}{|l|}{ Psychoticism } \\
\hline Yes & $7(25.0)$ & 0.623 & $0.249-1.560$ & 0.309 \\
\hline No & $54(34.8)$ & & & \\
\hline
\end{tabular}

${ }^{*} P$ values were derived by univariate binary logistic regression, $P<0.05$

is considered as significant. OR: Odds ratio, $\mathrm{Cl}$ : Confidence interval

showed these conditions were significant predictors for $\mathrm{DH}$.

The occurrence of sensitivity on denuded root surfaces as a result of GR or following periodontal therapy could be named as "root sensitivity" (RS), a concept suggested by the European Federation of Periodontology or cervical DH. In this sense, von Troil et al. ${ }^{[27]}$ in a systematic review about the prevalence of $\mathrm{DH} / \mathrm{RS}$ following periodontal therapy concluded this therapy cause RS and there are more than $50 \%$ of the patients from the selected studies who experienced this condition after periodontal treatment with an increased intensity during the next 3 weeks. Furthermore, Lin and Gillam ${ }^{[28]}$ determined that about 1 week following periodontal therapy, the RS/DH was ranging from $36.8 \%$ to $100 \%$ after which the prevalence subsequently decreased. However, 
von Troil et al. ${ }^{[27]}$ and Lin and Gillam ${ }^{[28]}$ mentioned that there are a lack of standardized data relating to evaluation of $\mathrm{DH} / \mathrm{RS}$ following periodontal therapy, for this reason, some aspects about DH/RS might be unclear. It seems that this therapy may remove from 20 to 50 micrometers of cementum exposing the dentinal tubules to external stimuli. ${ }^{[29,30]}$ Due to different cementum varieties that are found in human teeth, ${ }^{[31]}$ we really do not know whether $\mathrm{DH}$ can be attributed in $100 \%$ to the scaling and root planning.

Our findings about risk factors and the presence of $\mathrm{DH} / \mathrm{RS}$ also confirm the association between this condition and oral hygiene products such as toothpaste abrasivity (OR 1.881, 95\%, CI 1.010-3.502, P = 0.045). Addy and West ${ }^{[32]}$ mentioned tooth brushing with most toothpastes removes the smear layer to expose tubules and can exacerbate erosive loss of dentine. These findings thereby implicate tooth brushing with toothpaste in the etiology of DH. Philpotts et al. ${ }^{[33]}$ suggest that abrasivity of the toothpaste needs to be moderate in order to prevent removal of the underlying enamel and any exposed dentine.

We found a clinical but not statistical association among DH and several risk factors reported in the literature that would promote the loss of enamel and lead to DH. For example, it has been demonstrated that toothbrushes with medium and hard bristles cause more abrasion than soft toothbrushes. ${ }^{[34,35]}$ Our findings also showed $\mathrm{pH}$ of artificial fruit juices and frequency of carbonated drinks $\mathrm{p} / \mathrm{w}$ were clinically associated with $\mathrm{DH}$. Acidic soft drinks that include both fruit juices and carbonated beverages, induce the dissolution or erosion of dental enamel. ${ }^{[36]}$ Olley et al. ${ }^{[18]}$ observed in patients with tooth wear that this condition may be initiated whether they consume acidic beverages more frequently. In the same way, $\mathrm{pH}$ of alcohol can lead to loss of enamel. Mulic et al. ${ }^{[3]}$ demonstrated that there was a difference between wine tasters compared to nonwine tasters, the exposed group had a higher prevalence and more severely affected teeth surfaces.

We also want to comment on some clinical but not statistically psychological factors. Our results suggest that perceived psychological stress, obsessive-compulsive, and hostility symptoms may be risks factors for DH. Psychological stress increases the blood pressure, ${ }^{[38]}$ which may affect pulpal blood vessels and produce a severe sensitivity response to external stimuli. Obsessive-compulsive symptoms may be related to a cleaning compulsion favoring the frequency and the intensity of tooth brushing which may be associated with GR and loss of enamel and dentine. Otherwise, biological mechanism of hostility may contribute to the development of a late-adaptation syndrome with anxiety. ${ }^{[39]}$ Anxiety may contribute to muscle tension that exacerbate pain. ${ }^{[40]}$ This parafunction also named as bruxism may leads to hypersensitive teeth. ${ }^{[11]}$ Moreover, a chronic bruxism could favor the apparition of abfraction ${ }^{[42-44]}$ and attrition, as a result a more severe DH may be perceived. ${ }^{[45,46]}$

Since DH has been a persistent condition (chronic entity) and the therapies seem do not give long-lasting relief; it is very important to assess different risk factors in order to design more oral health education programs and develop more effective treatment options. For this reason, psychological evaluation may be important in patients with $\mathrm{DH}$. Consideration of psychological factors is important in assessing $\mathrm{DH}$ as well as other dental conditions.

Our sample size was inadequate to determine statistically significant associations between some risk factors and the presence of $\mathrm{DH}$. A larger sample would be required to provide adequate power to assess these factors. Finally, a small number of extant studies that have assessed $\mathrm{DH}$ etiology provide a limited context for comparison of our findings.

\section{CONCLUSION}

$\mathrm{DH}$ is relatively common and significant oral health problem. Oral hygiene products and periodontal conditions are important risk factors for $\mathrm{DH}$. Individuals with perceived psychological stress, obsessive-compulsive, and hostility symptoms increase a clinical risk for this entity. Targeting to dental counseling focused on oral hygiene products, periodontal therapy and a psychological evaluation may be promising in $\mathrm{DH}$ prevention.

\section{Acknowledgment}

We thank the School of Dentistry, Cooperative University of Colombia, Pasto clinic patients who accepted to participate in the dentine hypersensitivity assessment and Dr. María Isabel Portilla Cabrera, clinic coordinator, for upholding this project.

\section{Financial support and sponsorship}

The study was financially supported by the Comite para el Desarrollo de la Investigación (CONADI) at Cooperative University of Colombia. 


\section{Conflicts of interest}

There are no conflicts of interest.

\section{REFERENCES}

1. IASP Task Force on Taxonomy. Part III: Pain terms, a current list with definitions and notes on usage. In: Merskey H, Bogduk N, editors. Classification of Chronic Pain. $2^{\text {nd }}$ ed. Seattle: IASP Press; 1994. p. 209-214.

2. Dowell P, Addy M. Dentine hypersensitivity - A review. Aetiology, symptoms and theories of pain production. J Clin Periodontol 1983;10:341-50.

3. Bekes K, John MT, Schaller HG, Hirsch C. Oral health-related quality of life in patients seeking care for dentin hypersensitivity. J Oral Rehabil 2009;36:45-51.

4. Bamise CT, Olusile AO, Oginni AO, Dosumu OO. The prevalence of dentine hypersensitivity among adult patients attending a Nigerian teaching hospital. Oral Health Prev Dent 2007;5:49-53.

5. Que K, Ruan J, Fan X, Liang X, Hu D. A multi-centre and cross-sectional study of dentine hypersensitivity in China. J Clin Periodontol 2010;37:631-7.

6. Rees JS, Jin LJ, Lam S, Kudanowska I, Vowles R. The prevalence of dentine hypersensitivity in a hospital clinic population in Hong Kong. J Dent 2003;31:453-61.

7. Rahiotis C, Polychronopoulou A, Tsiklakis K, Kakaboura A. Cervical dentin hypersensitivity: A cross-sectional investigation in Athens, Greece. J Oral Rehabil 2013;40:948-57.

8. Costa RS, Rios FS, Moura MS, Jardim JJ, Maltz M, Haas AN. Prevalence and risk indicators of dentin hypersensitivity in adult and elderly populations from Porto Alegre, Brazil. J Periodontol 2014;85:1247-58.

9. Splieth $\mathrm{CH}$, Tachou A. Epidemiology of dentin hypersensitivity. Clin Oral Investig 2013;17 Suppl 1:S3-8.

10. West NX, Sanz M, Lussi A, Bartlett D, Bouchard P, Bourgeois D. Prevalence of dentine hypersensitivity and study of associated factors: A European population-based cross-sectional study. J Dent 2013;41:841-51.

11. Addy M, Pearce N. Aetiological, predisposing and environmental factors in dentine hypersensitivity. Arch Oral Biol 1994;39 Suppl: 33S-38S.

12. Bernhardt O, Gesch D, Schwahn C, Mack F, Meyer G, John U, et al. Epidemiological evaluation of the multifactorial aetiology of abfractions. J Oral Rehabil 2006;33:17-25.

13. Naidu GM, Ram K C, Sirisha NR, Sree Y S, Kopuri RK, Satti NR, et al. Prevalence of dentin hypersensitivity and related factors among adult patients visiting a dental school in andhra pradesh, southern India. J Clin Diagn Res 2014;8:ZC48-51.

14. Engel GL. The need for a new medical model: A challenge for biomedicine. Science 1977;196:129-36.

15. Kiecolt-Glaser JK, McGuire L, Robles TF, Glaser R. Psychoneuroimmunology: Psychological influences on immune function and health. J Consult Clin Psychol 2002;70:537-47.

16. Bartley EJ, Fillingim RB. Sex differences in pain: A brief review of clinical and experimental findings. Br J Anaesth 2013;111:52-8.

17. Wiesenfeld-Hallin Z. Sex differences in pain perception. Gend Med 2005;2:137-45.

18. Olley RC, Moazzez R, Bartlett D. The relationship between incisal/ occlusal wear, dentine hypersensitivity and time after the last acid exposure in vivo. J Dent 2015;43:248-52.

19. Dorner TE, Muckenhuber J, Stronegger WJ, Ràsky E, Gustorff B, Freidl W. The impact of socio-economic status on pain and the perception of disability due to pain. Eur J Pain 2011;15:103-9.

20. Estrela C, Guedes OA, Silva JA, Leles CR, Estrela CR, Pécora JD. Diagnostic and clinical factors associated with pulpal and periapical pain. Braz Dent J 2011;22:306-11.

21. Hefferren JJ. A laboratory method for assessment of dentrifrice abrasivity. J Dent Res 1976;55:563-73.

22. Remor E. Psychometric properties of a European Spanish version of the perceived stress scale (PSS). Span J Psychol 2006;9:86-93.

23. Bonicatto S, Dew MA, Soria JJ, Seghezzo ME. Validity and reliability of symptom checklist '90 (SCL90) in an Argentine population sample. Soc Psychiatry Psychiatr Epidemiol 1997;32:332-8.
24. Gempp-Fuentealba R, Avendaño-Bravo C. Normative data and psychometric properties of the SCL-90-R in Chilean college students. Ter Psicol 2008;26:39-58.

25. Bahsi E, Dalli M, Uzgur R, Turkal M, Hamidi MM, Colak H. An analysis of the aetiology, prevalence and clinical features of dentine hypersensitivity in a general dental population. Eur Rev Med Pharmacol Sci 2012;16:1107-16.

26. Taani Q, Awartani F. Clinical evaluation of cervical dentin sensitivity (CDS) in patients attending general dental clinics (GDC) and periodontal specialty clinics (PSC). J Clin Periodontol 2002;29:118-22

27. von Troil B, Needleman I, Sanz M. A systematic review of the prevalence of root sensitivity following periodontal therapy. J Clin Periodontol 2002;29 Suppl 3:173-7.

28. Lin YH, Gillam DG. The prevalence of root sensitivity following periodontal therapy: A systematic review. Int J Dent 2012;2012:407023.

29. Uchida A, Wakano Y, Nishida M, Terayama E, Kida T, Fukuyama O, et al. The effect of periodontal dressing containing $2 \%$ sodium fluoride in treatment of dentin hypersensitivity following periodontal surgery (author's transl). Nihon Shishubyo Gakkai Kaishi 1979;21:463-70.

30. Wallace JA, Bissada NF. Pulpal and root sensitivity rated to periodontal therapy. Oral Surg Oral Med Oral Pathol 1990;69:743-7.

31. Bosshardt DD, Selvig KA. Dental cementum: The dynamic tissue covering of the root. Periodontol 2000 1997;13:41-75.

32. Addy M, West NX. The role of toothpaste in the aetiology and treatment of dentine hypersensitivity. Monogr Oral Sci 2013;23:75-87.

33. Philpotts CJ, Weader E, Joiner A. The measurement in vitro of enamel and dentine wear by toothpastes of different abrasivity. Int Dent J 2005;55 3 Suppl 1:183-7.

34. Carvalho Rde S, Rossi V, Weidlich P, Oppermann RV. Comparative analysis between hard- and soft-filament toothbrushes related to plaque removal and gingival abrasion. J Clin Dent 2007;18:61-4.

35. Zanatta FB, Bergoli AD, Werle SB, Antoniazzi RP. Biofilm removal and gingival abrasion with medium and soft toothbrushes. Oral Health Prev Dent 2011;9:177-83.

36. West NX, Hughes JA, Addy M. The effect of $\mathrm{pH}$ on the erosion of dentine and enamel by dietary acids in vitro. J Oral Rehabil 2001;28:860-4.

37. Mulic A, Tveit AB, Hove LH, Skaare AB. Dental erosive wear among Norwegian wine tasters. Acta Odontol Scand 2011;69:21-6.

38. Kulkarni S, O'Farrell I, Erasi M, Kochar MS. Stress and hypertension. WMJ 1998;97:34-8.

39. Spalletta G, Romeo E, Bonaviri G, Bernardi G, Caltagirone C, di Michele F. Preliminary evidence for an association between aggressive and hostile behaviour and $3 \alpha, 5 \alpha$-tetrahydroprogesterone plasma levels in schizophrenia. J Psychiatry Neurosci 2005;30:49-52.

40. Bateson M, Brilot B, Nettle D. Anxiety: An evolutionary approach. Can J Psychiatry 2011;56:707-15.

41. Ghafournia M, Hajenourozali Tehrani M. Relationship between bruxism and malocclusion among preschool children in Isfahan. J Dent Res Dent Clin Dent Prospects 2012;6:138-42.

42. Grippo JO. Tooth flexure. J Am Dent Assoc 1991;122:13.

43. Lee WC, Eakle WS. Possible role of tensile stress in the etiology of cervical erosive lesions of teeth. J Prosthet Dent 1984;52:374-80.

44. Spranger H. Investigation into the genesis of angular lesions at the cervical region of teeth. Quintessence Int 1995;26:149-54.

45. McGuire MK, Nunn ME. Prognosis versus actual outcome. III. The effectiveness of clinical parameters in accurately predicting tooth survival. J Periodontol 1996;67:666-74.

46. Addy M. Tooth brushing, tooth wear and dentine hypersensitivity-Are they associated? Int Dent J 2005;55 4 Suppl 1:261-7.

\begin{tabular}{|l|l|}
\hline \multicolumn{2}{|c|}{ Access this article online } \\
\hline Quick Response Code: & \\
& Website: \\
\hline
\end{tabular}

